\title{
Awareness of Academic Advisory Roles of Lecturers by Education Undergraduates in University of Port Harcourt, Nigeria
}

\author{
Dr. Chikwe Agbakwuru \\ Department of Educational Psychology, Guidance and Counselling, \\ Faculty of Education, University of Port Harcourt, Nigeria \\ Dr. Stella Ugwueze \\ Department of Psychology \\ College of Management and Social Sciences, Renaissance University, \\ Ugbawka, Enugu, Nigeria
}

\begin{abstract}
This study investigated awareness of academic advisory roles of lecturers by education undergraduates in University of Port Harcourt, Nigeria. The design of the study was descriptive survey, while the population was 1,460 regular final year undergraduates of the university 2018/2019 academic session. The sample was 500 students who were composed through proportionate random sampling technique from seven departments of Faculty of Education that had final year students. Relevant data were collected from the sample through personal contact method of administration of copies of researchers' made Academic Advisory Awareness Questionnaire (AAAQ). The reliability was established through the Pearson Product Moment formula and for the three sections of the instrument it was $0.71,0.76$ and 0.72 while the overall reliability co-efficient was 0.73 . Data were analyzed with mean and standard deviation statistics. The results show that the respondents have faint knowledge of the roles of an academic advisor, their assessment of the effectiveness of the academic advisers is poor and their perceived impediments to effective academic advising is also slightly poor. The results were discussed and some recommendations were also made. One of the recommendations is that counsellor educators, counsellors in the counselling unit in the student affairs department and the director of counselling services in the university should sensitize/enlighten the students on the roles of their academic advisers to them.
\end{abstract}

DOI: $10.7176 / \mathrm{JEP} / 11-6-24$

Publication date: February $29^{\text {th }} 2020$

\section{Background of the study}

Successful academic career requires among other things, the adjustment of the learner to the learning environment. Adjustment to the learning environment demands bringing the learners behaviours in conformity with the norms of the school setting. It is principally designed to facilitate the adaptation of the learner to school life/culture (Agbakwuru, 2019). Those who adjust successfully feel relaxed, happy, comfortable and also exhibit enthusiasm in pursuing academic goals. On the other hand, those who fail to adjust successfully experience the reverse. In recognition of the importance of school adjustment in successful academic career, every school strives to enhance the adjustment of its students to school life / culture.

One major way universities in particular adopt to facilitate this required adjustment of their students to academic culture is through academic advising. Academic advising is a series of intentional interactions with a curriculum, pedagogy, and a set of students learning outcomes (Bitz, 2013). It is concerned with academic staff guiding and directing students assigned to them on the academic regulations and activities to ensure they maximize their academic potentials (Alvan Ikoku Federal College of Education, Owerri, N.D.). In academic advising assistance is given to students by academic staff called academic advisor to realize the maximum educational benefits to them by helping them to better understand themselves and to learn to use the resources of the institution to meet their special educational needs and aspirations (Crockett, 2008). By so doing, academic advising synthesizes and contextualizes students' educational experiences within the frameworks of their aspirations abilities and lives to extend learning beyond campus boundaries and time frame (National Academic Advising Association, 2006). Research repost (Fowler \& Boylan, 2010) has shown that academic advising increase students satisfaction and mitigate their feelings of isolation or disconnection from the institution as a whole. This is in addition to its positive effects in increasing university students' retention and graduation and reduced attrition and withdrawal rates (Gravel, 2012).

The need for effective academic advising in the contemporary Nigerian university system cannot be over emphasized. This is so because there is an apparent decline in the standard of university education, low level of academic motivation among many students, gross under achievement of some bright students, increased crime rate by students, etc. Furthermore, many students in the university possess diverse educational backgrounds and abilities. By assisting them in effective decision making and providing them with current and reliable information about university policies, procedures, resources and programmes through academic advisory services, the 
university enhances their orientation and continuing orientation programme in the school. This gives them a sense of direction and purpose in their academic pursuit.

The academic advisor has many duties in the university. Review of research reports (Harrison, 2009; National Academic Advising Association, 2006; Fowler \& Boylan, 2010 \& Gravel, 2012) have identified the duties of an academic advisor to include

- $\quad$ Offering assistance to students in evaluating skills and talents.

- $\quad$ Advising students in the selection of course work and other academic programmes.

- $\quad$ Helping students to combine their abilities with their interests and thus develop a plan of action that will produce the desired outcome for them.

- $\quad$ Locating and connecting students with the best opportunities.

- $\quad$ Evaluating test results and other factors that indicate the aptitudes possessed by the students.

- Teaching and inspiring students for academic excellence.

- $\quad$ Listening and providing accurate information to students.

- $\quad$ Keeping good records and recognizing accomplishments of students.

- $\quad$ Sustaining an environment of academic and professional excellence for students and educational team members.

- Supporting students' life and learning through students advocacy, academic coaching, customer service, campus and community referrals and institutional outreach.

- Working closely with all campus departments to support efforts and development.

Alvan Ikoku Federal College of Education, Owerri (N.D: 2-5) also listed the roles of an academic advisor as follows:

- Mentorship and guardian of students.

- Helping students to know courses to register and directing them on how to register for those courses.

- $\quad$ Ensuring effective enrollment of students in their departments during the registration period.

- $\quad$ Ensuring that students stick to the required academic load for each semester.

- $\quad$ Helping students to change courses when it becomes necessary.

- $\quad$ Helping students to understand and adhere to school regulations.

- $\quad$ Keeping students departmental files after screening by the admissions office.

- Maintaining office hours for students' consultation.

- $\quad$ Promotion of students' well-being through interactions and interviews.

- $\quad$ Liaising with relevant departments, bodies and agencies for the promotion of students' well-being.

- Liaising with parents/guardians of students for the enhancement of students' well-being.

- Collation, computation and reconciliation of students results with examination officers of the school.

- $\quad$ Showing students their moderated results.

- Compilation of completed course registration forms for submission to appropriate departments/units.

To be able to carry out these functions, an academic adviser must be effective. Effectiveness in academic advising means the ability of the academic adviser to bring about the desired behaviour change in the students through educational activities, (Durkin cited in Ojiako, 2014). Such behaviour changes or learning outcomes are largely assessed through the learners' academic achievements. This is why Goe, Bell and Little (2008) stated that the teachers/academic adviser's effectiveness is measured through his/her ability to produce higher than expected gains in students standardized test scores. An effective academic adviser is aware of his roles and actively pursues his goals. He performs his services with the intention of enhancing students' optimal learning through direct as well as indirect actions.

Unfortunately, despite the enormous benefits of academic advising, much of the desired improvement in students' behaviour, learning and school adjustment has not been realized. This is probably due to the fact that many students in Nigerian universities are not fully aware of the roles of their academic advisors. The presumed ignorance of the full roles of their academic advisors seems to have prevented them from tapping fully the benefits of academic advising. This is so because one can only benefit fully from what one is fully aware of its existence and benefits. Furthermore, most of the so-called academic advisers are neither education specialists in general nor guidance specialists in particular even though academic advisory roles are largely the roles of professional guidance counsellors to students. Coupled with these issues is that no one knows how effective the academic advisors are in performing their duties since there is an apparent lack of research reports on the effectiveness of academic advisers based on the opinion of their students. In the present circumstances, the problem of this study posed as a research question is "what is education undergraduates' level of awareness of the roles of an academic adviser in the university? The answer to this question will certainly fill a missing gap in knowledge regarding education undergraduates' awareness of the roles of an academic adviser in the university. The results of the study will be useful to lecturers, university administrators, policy makers and the students themselves in fashioning out 
better ways of enhancing students desired behaviour change, academic achievement and school adjustment through robust academic advisory services.

The study was guided by the following research questions:

1. What roles do education undergraduates ascribe to their academic advisers?

2. What is the assessment of education undergraduates regarding the effectiveness of their academic advisers in carrying out their academic advisory duties?

3. What do education undergraduates consider to be the impediments of effective academic advisory by their advisors?

\section{Methodology}

This study was carried out in the University of Port Harcourt, Federal Republic of Nigeria. The design of study is descriptive survey. The population of study consists of 1,460 regular final year undergraduates of 2015/2016 academic session in the Faculty of Education of the University. A sample of 500 final year education undergraduates was drawn through proportionate random sampling technique from seven departments of the faculty of education that had final year students. The restriction of the population and sample to regular final year education undergraduates was taken because this category of final year undergraduates are relatively younger than most of the part-time and sandwich final year students and as such, they have more need for effective academic advising to help them maximize their academic potentials. Again, their discipline as education students put them in a better position than other undergraduates in other faculties in knowing how and what it takes to facilitate effective school adjustment of students. In addition, the final year students have had a lot of experiences in the school and with their academic advisers. This wealth of experiences put them in a vantage position to give correct and reliable information about academic advisory services in their faculty in particular and university in general.

Relevant data for answering the three research questions posed for the study were gathered by the researchers through the direct contact method of administration of copies of Academic Advisory Awareness Questionnaire (AAAQ) on the respondents. The questionnaire was developed by the researchers through logical reasoning as well as through review of literature (Ojiako 2014; Asiabaka \& Emenalo, 2011; \& Alvan Ikoku Federal College of Education, N.D.). It contains a total of 26 items which were designed to elicit information for answering the three research questions posed for the study. These items were grouped under three sections which correspond with the three research questions posed for the study. The items were structured in the pattern of a modified 4-point Likert type questionnaire of strongly agree (SA), agree (A), disagree (D) and strongly disagree (SD) with scoring weight of 4points, 3points, 2points and 1 point respectively. The sample was asked to indicate their responses for each item in the appropriate column by marking a tick.

To ascertain the reliability co-efficient of the instrument, its field trial was carried out with 50 regular final year education undergraduates in Ignatius Ajuru University of Education, Port Harcourt, Nigeria. After an interval of two weeks, the same instrument was re-administered to the same subjects and their scores in the two administrations of the instrument were correlated with Pearson Product Moment Correlation formula. The obtained reliability co-efficient were 0.71 for ascribed roles, 0.76 for effectiveness of academic advisors and 0.72 for impediments of effective academic advisory services while the overall reliability co-efficient of the instrument was 0.73 . These reliability values show that the instrument is reliable for the study.

All the copies of questionnaire administered were completed and returned as the researchers waited and collected them immediately after administration and completion. The responses of the sample were collated and scored by the researchers. Statistical analysis was carried out by the researchers item by item with mean and standard deviation statistics. In carrying out the analysis, 2.50 (that is midpoint score between agree and disagree) was take as the criterion or cut-off mean score.

\section{Results:}

Results of statistical analysis of data are presented in the following tables: 
Table 1: Students knowledge of the roles of an academic adviser

\begin{tabular}{|c|c|c|c|c|c|}
\hline $\mathrm{S} / \mathrm{N}$ & Roles & $\mathrm{N}$ & $\bar{X}$ & S.D & Criterion \\
\hline 1. & Mentorship and guardian to students & \multirow{11}{*}{ \& } & 2.71 & 0.65 & \multirow{12}{*}{$\stackrel{2}{n}$} \\
\hline 2. & Directing students on courses meant for their programmes & & 3.50 & 1.23 & \\
\hline 3. & Guiding students on course registration & & 3.53 & 0.99 & \\
\hline 4. & Helping students to understand and adhere to school regulations & & 2.46 & 0.87 & \\
\hline 5. & Keeping custody of students departmental files. & & 2.35 & 0.79 & \\
\hline 6. & Promotion of students well-being through interactions and interviews & & 1.97 & 1.01 & \\
\hline 7. & $\begin{array}{l}\text { Liaising with relevant departments, bodies and agencies for the } \\
\text { enhancement of students' well-being. }\end{array}$ & & 1.99 & 0.94 & \\
\hline 8. & $\begin{array}{l}\text { Collation, computation and reconciliation of students results with } \\
\text { examination officers of the school }\end{array}$ & & 4.00 & 0.00 & \\
\hline 9. & Showing students their moderated results. & & 4.00 & 0.00 & \\
\hline 10 . & $\begin{array}{l}\text { Compilation of completed course registration forms for submission to } \\
\text { appropriate departments/units }\end{array}$ & & 2.01 & 0.68 & \\
\hline \multirow[t]{2}{*}{11.} & $\begin{array}{l}\text { Supporting student life and learning through student advocacy, academic } \\
\text { coaching, customer service, campus and community referrals and } \\
\text { institutional outreach. }\end{array}$ & & 1.30 & 0.93 & \\
\hline & Grand mean score & & 2.49 & & \\
\hline
\end{tabular}

The result on table 1 shows that items $1,2,3,8$ and 9 only have means scores that are equal to or greater than the criterion mean score of 2.50. This means that the only roles of an academic adviser which the students know are:

- Mentorship and guardian to students.

- $\quad$ Directing students on courses mean for their programme.

- Guiding students on course registration.

- Collation, computation and reconciliation of students results with examination officers of the school.

- $\quad$ Showing students their moderated results.

Furthermore, the grand mean score of 2.49 is slightly lower than the criterion mean score of 2.50 . The conclusion which was drawn from this is that the undergraduates do not have adequate knowledge of the roles of an academic adviser.

Table 2: Students assessment of the effectiveness of their academic advisers

\begin{tabular}{|c|c|c|c|c|c|}
\hline $\mathrm{S} / \mathrm{N}$ & Roles & $\mathrm{N}$ & $\bar{X}$ & S.D & Criterion \\
\hline & My academic adviser is: & & & & \\
\hline 1. & Dedicated to his students & \multirow{8}{*}{ 유 } & 2.89 & 1.52 & \multirow{8}{*}{$\stackrel{n}{i}$} \\
\hline 2. & Serious with his academic advisory duties & & 2.15 & 0.79 & \\
\hline 3. & $\begin{array}{l}\text { Feels responsible for the achievement and progress of his } \\
\text { students }\end{array}$ & & 1.84 & 1.03 & \\
\hline 4. & Inspires the students to learn & & 2.76 & 1.24 & \\
\hline 5. & Respected and not feared by the students & & 2.47 & 0.99 & \\
\hline 6. & Interacts with students in a healthy manner & & 2.66 & 0.95 & \\
\hline 7. & $\begin{array}{l}\text { Monitors students progress report and advises them } \\
\text { accordingly }\end{array}$ & & 2.79 & 1.03 & \\
\hline 8. & Gives students adequate attention & & 1.85 & 0.57 & \\
\hline & Grand mean score & & 2.43 & & \\
\hline
\end{tabular}

The result on table 2 shows that the mean scores of items 1, 4, 6, and 7 are equal to or greater than the criterion mean score of 2.50. This means that they assessed their academic advisers to be effective only in:

- $\quad$ inspiring them to learn,

- their dedication to the students,

- $\quad$ interacting with them in a healthy manner and

- $\quad$ monitoring their progress report and advising them accordingly.

Furthermore, the grand mean score of 2.43 is also slightly below the criterion mean score of 2.50 . This shows that the students' assessment of the effectiveness of their academic advisers is poor or slightly below average. 
Table 3: Students perceived impediments to effective academic advising

\begin{tabular}{|c|c|c|c|c|c|}
\hline $\mathrm{S} / \mathrm{N}$ & Roles & $\mathrm{N}$ & $\bar{X}$ & S.D & Criterion \\
\hline 1. & $\begin{array}{l}\text { Poor knowledge of the roles of an academic adviser by some of } \\
\text { the lecturers. }\end{array}$ & \multirow{6}{*}{ 요 } & 2.44 & 1.06 & \multirow{6}{*}{$\stackrel{n}{i}$} \\
\hline 2. & $\begin{array}{l}\text { Large number of supervisees/students assigned to each } \\
\text { academic adviser }\end{array}$ & & 3.06 & 0.55 & \\
\hline 3. & Too much work load on academic advisers & & 2.88 & 0.77 & \\
\hline 4. & $\begin{array}{l}\text { Inadequate motivation from university administrators and the } \\
\text { government }\end{array}$ & & 2.79 & 0.65 & \\
\hline 5. & $\begin{array}{l}\text { On chalent attitude of some academic advisers to academic } \\
\text { advisory roles }\end{array}$ & & 1.83 & 0.47 & \\
\hline \multirow[t]{2}{*}{6.} & $\begin{array}{l}\text { Expectation of gratification from students by some academic } \\
\text { advisors }\end{array}$ & & 1.96 & 0.67 & \\
\hline & Grand mean score & & 2.49 & & \\
\hline
\end{tabular}

The result on table 3 show that students perceived the following as impediments to effective academic advising in the university:

- $\quad$ Large number of supervisees/students assigned to each academic adviser.

- $\quad$ Too much work load on academic advisers.

- Inadequate motivation from university administrators and the government

These conclusions are drawn because it is only these three items that have mean scores that are equal to or greater than 2.50 which is the criterion mean score. Also, the grand mean score of 2.49 is slightly below the criterion mean. The conclusion which was drawn from this is that students perceived impediments to effective academic advising are slightly poor.

\section{Discussion of Findings}

The result on table one shows that education undergraduates lack adequate knowledge of the roles of an academic adviser. This situation is unfortunate in the case of final year education undergraduates who in a matter of few months will be qualified to minister at the altar of education affairs in the country. The result is also worrisome because without adequate knowledge of the roles of an academic adviser, students cannot draw close to them. This situation calls for sensitization/enlightenment of the students on the roles of their academic advisers. This can be achieved during orientation programme of new students and continued orientation programme for old or returning students.

In a related way, statistical analysis of data show that students assessment of the effectiveness of their academic advisers is poor or slightly below average. This result is not surprising because one can only assess one's performance of one's roles effectively when one has full knowledge of one's roles. In the present situation, the undergraduates have a faint knowledge of the roles of their academic advisers hence they cannot objectively assess whether they are effective or not in the performance of those roles.

Finally, the result of research question three shows that students perceived impediments of effective academic advising is slightly poor. This type of result is also expected because the respondents lack adequate knowledge of the roles of an academic adviser. Since they have faint knowledge of the roles, there is no way they will know fully the impediments to the effective discharge of the roles.

\section{Recommendations}

In the light of the results of this study, the following recommendations are hereby made:

- Counsellor educators in the university, counsellors in the student affairs department and the director of counselling services in the university should sensitize/enlighten the students on the roles of their academic advisers to them.

- $\quad$ The university administrators should appoint more academic advisers to lessen the burden posed by few academic advisers serving many students.

- $\quad$ Adequate fringe benefits should be paid to academic advisers as a way of motivating them in their duties.

\section{References}

Agbakwuru, C. (2009). School adjustment. Owerri: Joe Mankpa Publisher.

Alvan Ikoku Federal College of Education, Owerri, Imo State (N.D.). Academic advising handbook for degree programme. A Production of Anti-corruption and Transparency Monitoring Unit/Academic Planning Unit.

Asiabaka, I.P. \& Emenalo, F.C. (2011). Management of teaching as a profession. Owerri: Unique books Websmedia Communication Ltd.

Bitz, K. (2013). Measuring adviser relationship perceptions among first year students at a small Midwestern 
University. NACADA Journal, 30(2), 52-64.

Crockett, D.S. (2008) (Ed.). Academic advising: a resource document. Lowa City: Service No. ED189906.

Fowler, P.R., \& Boylan, H.R. (2010). Increasing student success and retention: a multidimensional approach. Journal of Development Education, 34(2), 2-10.

Geo, L.; Bell, C. \& Little, O. (2008). Approaches to evaluating teachers effectiveness in research synthesis. Retrieved from www.tqsource.org.

Gravel, C.A. (2012). Student - adviser interaction in undergraduate online degree programmes: a factor in student retention. NACADA Journal, 32(2), 56-67.

Harrison, E. (2004). Faculty perception of academic advising. Nursing Education Perspectives, 30(4), $229-233$.

National Academic Advising Association (2006). NACADA Concept of academic advising.

Ojiako, C.A. (2014). Teacher effectiveness. In Teachers, schools and society. N.C. Okorie, L.E.B. Igwe, J.D. Asodike, V.C. Onyeike \& R.O. Anyaogo (Eds). Port Harcourt: Pearl Publishers, pp. 93-110. 